\title{
Intensity level as sustainable energy: Analysis of the conversion of energy stored on cicadas sound waves
}

\author{
Rofiqul Umam $^{1 *}$, Endah Kinarya Palupi ${ }^{1}$, Khusnul Yakin ${ }^{2,3}$, Mochamad Iqbal ${ }^{4,5}$, RahmatNawi \\ Siregar $^{6,7}$, Irzaman $^{8}$ \\ ${ }^{1}$ School of Science and Technology, Kwansei Gakuin University, Japan \\ ${ }^{2}$ Faculty of Sciences and Technology, Kanazawa University, Japan \\ ${ }^{3}$ Departmen of Physics, Maulana Malik Ibrahim Islamic State University Malang, Indonesia \\ ${ }^{4}$ Faculty of Sciences and Technology, Kyoto University, Japan \\ ${ }^{5}$ Geological Engineering Study Program, Institut Teknologi Sumatera, Indonesia \\ ${ }^{6}$ Department of Physics, Institut Teknologi Sumatera, Indonesia \\ ${ }^{7}$ Department of Physics, Gadjah Mada University, Indonesia \\ ${ }^{8}$ Department of Physics, IPB University, Indonesia \\ *Corresponding Address:rofiqulumam.geoscience@gmail.com
}

\begin{tabular}{|c|c|}
\hline Article Info & ABSTRACT \\
\hline Article history: & $\begin{array}{l}\text { In this study, the researchers measured cicadas' sound waves, considering that } \\
\text { cicadas are mostly found in rural areas. The intensity level meter (AMTAST }\end{array}$ \\
\hline Received: August30, 2021 & AMF003) was used with time variations (9:00 JST; 12:00 JST; and 15:00 \\
\hline Accepted: October15, 2021 & JST). Measurements of air temperature differences (Krisbow Temperature \& \\
\hline Published: October30, 2021 & $\begin{array}{l}\text { Humidity Data Logger) were also carried out, and weather conditions were } \\
\text { also considered in data collection using satellite data from Himawari, Japan. }\end{array}$ \\
\hline Keywords: & $\begin{array}{l}\text { The interpretation results of intensity level's trend measured at } 3: 00 \mathrm{pm} \mathrm{JST} \\
\text { were decreased concerning the changes in days. Meanwhile, the measurement }\end{array}$ \\
\hline $\begin{array}{l}\text { Intensity Level; } \\
\text { Intensity; } \\
\text { Acoustic Power; } \\
\text { Energy; } \\
\text { Cicadas. }\end{array}$ & $\begin{array}{l}\text { at } 09: 00 \text { am and } 12: 00 \mathrm{pm} \text { JST did not show a decrement concerning the } \\
\text { changes in days ( } 31 \text { days in total). These results show that temperature } \\
\text { changes (towards autumn) can affect the intensity level of sound waves. In } \\
\text { addition, slightly different intensity levels can affect large changes in acoustic } \\
\text { power or the produced sound. }\end{array}$ \\
\hline
\end{tabular}

(C) 2021 Physics Education Department, UIN Raden Intan Lampung, Indonesia.

\section{INTRODUCTION}

Japan is a country with four seasons, namely spring, summer, autumn, and the last is winter. In August, Japan experiences summer, which has a reasonably high temperature compared to other months. One of the very identical insects in summer is the Cicadas (Sueur \& Sanborn, 2003). Cicadas are insects that very much appear and dwell on certain trees in Japan with a loud sound. This animal is indeed a characteristic symbol of the arrival of summer (Figure 1). According to the researchers, the life cycle of this animal is fascinating, where the female will lay her eggs in the crevices of the wood twigs. When they hatch, the larvae will fall to the ground and enter to eat their food, and the cicadas larvae are suitable to be underground because they are protected from predators (Stölting et al., 2002). According to research, only male Cicadas make sounds to invite their mates and mate. This animal's favorite tree is usually the Chestnut tree when it develops. Usually, this Chestnut tree will develop in early June, right when it rains in early summer, so that the weather will become humid and Cicadas begin to move up the tree from the ground (Josephson \& Young, 1979).

The sound waves emitted by cicadas are very high. This sometimes causes some people to feel disturbed by the sound waves 
emitted, so that it harms life in Japan in the summer, especially for the elderly (WHO, 2003).

Generally, during summer, some people need a calm atmosphere, especially the elderly. In addition, a room equipped with a cooler such as an Air Conditioner (AC) is a must-have tool for people.Summer is one of the seasons that requires more electrical energy than other seasons (Fonseca \& Correia, 2007). This is because electronic devices (Mashhadi et al., 2016), such as refrigerators and air conditioners, are used continuously during the summer. Thus, some countries with sub-tropical conditions, one of which is Japan, require more energy in the summer (Sueur \& Sanborn, 2003). Although solar panels and other alternative energy are developing very advanced in this country, electrical energy is still in great need in rural areas.

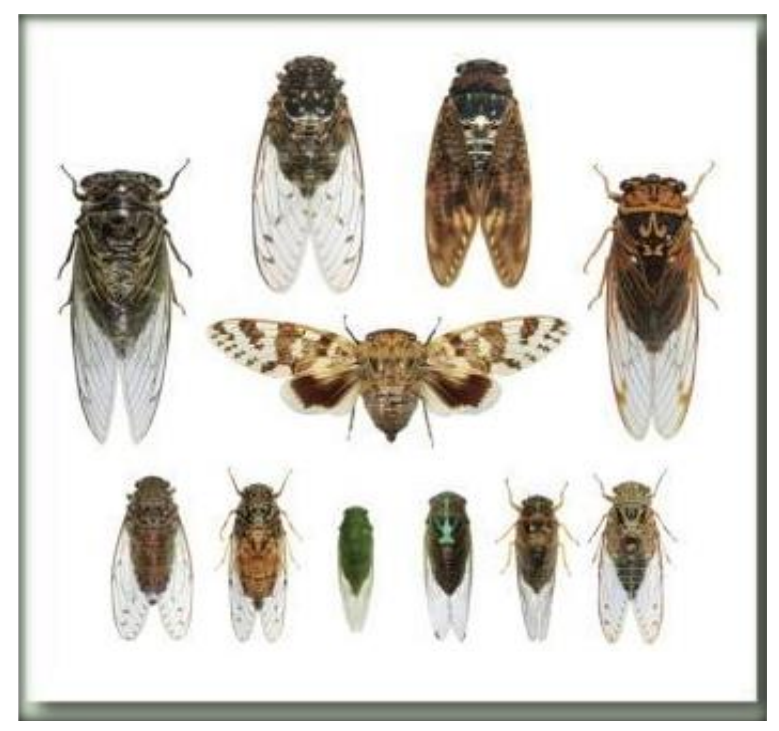

Figure 1. The Cicadas(Cicadae) of Japan(Sueur \& Sanborn, 2003)

In this study, we measured cicadas' sound waves, considering that cicadas are mostly found in rural areas. In addition, researchers have not widely carried out observations regarding the use of sound waves in the form of intensity levels released by cicadas to be converted into electrical energy. Research results from several previous studies say that the resonator produced by cicadas is not proportional to the size of the insect. Thus, in this study, we wanted to observe and predict the potential use of sound waves produced by cicadas in generating electrical energy.

\section{Equation of Resonant Sound Waves in the Air}

Sound waves or resonance in the air is a nonlinear process. Many factors cause sound waves in the air to be nonlinear (humidity, wind, rain, etc.). Resonating sound waves can be converted into energy and regressed in three modes. The description of the mathematical model in the interaction of sound waves can be derived as follows in the Burgers Equation, which describes the propagation of a finite-amplitude wave in a medium (Yang et al., 2014):

$$
\begin{aligned}
& \frac{\partial v}{\partial x}-\frac{\beta}{c_{o}^{2}} v \frac{\partial v}{\partial \tau}=\frac{b}{2 \rho_{o} c_{o}^{3}} \frac{\partial^{2} v}{\partial \tau^{2}} \\
& b=\kappa\left(1 / C_{v}-1 / C_{p}\right)+(\eta+4 \xi / 3)
\end{aligned}
$$

Where $x$ is the distance $(\mathrm{m}) ; \tau=t-x / c_{o}$ is a function of time $(\mathrm{s}) ; t$ is time $(\mathrm{s}) ; c_{o}$ is the speed of sound $(\mathrm{m} / \mathrm{s})$; $v$ is the function of distance and time $(\mathrm{m} / \mathrm{s}) ; \rho_{o}$ is the density of the medium $\left(\mathrm{kg} / \mathrm{m}^{3}\right) ; \quad \beta$ is the nonlinear parameter of the medium. $\xi$ is Shear viscosity $\left(\mathrm{N} \cdot \mathrm{s} / \mathrm{m}^{2}\right) ; \eta$ is bulk viscosity $\left(\mathrm{N} \cdot \mathrm{s} / \mathrm{m}^{2}\right) ; \kappa$ isa thermal conductivity; $C_{v}$ isa specific heat at constant volume $(\mathrm{K}) ; C_{p}$ isa specific heat at constant pressure (Atm).

Attenuation is the weakening of wave sources caused by the longer distance that wave sources must travel and because the frequency of the wave sources is getting higher (Shi \& Liu, 2019). The sound wave's energy will decrease along with its propagation from the source because the sound wave spreads out in a wide field. Its energy is spread over a large area. Sound waves propagating through water media will experience energy loss (Gheibi \& Hedayat, 2020) caused by wave propagation, energy absorption, and reflections occurring at the waters' bottom or surface (Yang et al., 2014). In reality, the intensity level measured in this study is a sound wave that has experienced attenuation due to attenuation. This allows 
that the magnitude of the actual intensity level is greater than the measurement results.

The intensity of the sound wave will decrease with increasing distance from the sound source (Japan Meteorological Agency, 2018). Thus, when there is an interaction of waves $(l)$ in a medium, the number of waves must satisfy the following resonance relationship (Yang et al., 2014):

$$
\left\{\begin{array}{l}
k_{a}+k_{b}=k_{c} \\
k_{b}-k_{a}=k_{d}
\end{array}\right.
$$

$k_{a}$ isthe wavenumber of the signal wave; $k_{b}$ isthe wavenumber of the pump wave; $k_{c}$ and $k_{d}$ are the wavenumbers of the sumfrequency wave and the difference-frequency wave (Courtney \& Courtney, 2008).

Based on equation (3), if there are $n$ columns signal waves and $m$ columns pump waves, the sum-difference frequency waves are $m n$. In this case, the relationship is:

$$
l=n+m+2 m n
$$

Where $l$ is the interaction of waves in a medium. So, the vibration velocity at any position in the propagation process can be expressed as:

$$
\begin{aligned}
v=\sum_{l=1}^{n+m+2 m n} A_{l}(x) \exp \left(i \omega_{l} \tau\right) \\
+A_{l}^{*}(x) \exp \left(-i \omega_{l} \tau\right)
\end{aligned}
$$

Where $A_{l}$ is the complex amplitude of acoustic velocity $(\mathrm{m})$ and $\omega_{l}$ is the angular frequency of sound $(\mathrm{Hz})$, according to the order of increasing frequency, the signal waves are numbered from 1 to $n$. The pump waves are from $(n+1)$ to $(n+m)$, sumfrequency waves are from $(n+m+1)$ to $(n+m+m n)$, and difference-frequency waves are from $(n+m+m n+1)$ to $(n+$ $m+2 n m)$. However, when $\forall l \in[1: n]$, the signal wave $A_{l}$ satisfies the following relationship with the pump wave.

$$
\left\{\begin{array}{l}
\omega_{l}+\omega_{1}=\omega_{H_{1}^{l}}, \ldots, \omega_{l}+\omega_{m}=\omega_{H_{m}^{l}} \\
\omega_{i}-\omega_{1}=\omega_{C_{1}^{l}}, \ldots, \omega_{m}-\omega_{l}=\omega_{C_{m}^{l}}
\end{array}\right.
$$

Where $H$ and $C$ represent the sumfrequency and difference-frequency $(\mathrm{Hz})$, their subscripts are the numbers of pump waves. By substituting equation (5) into equation (1), the following equation is obtained:

$$
\begin{aligned}
\frac{d A_{l}}{d x}-i \frac{\omega_{l}}{c} A_{l}+ & \frac{b \omega_{l}^{2}}{2 \rho_{o} c_{o}{ }^{3}} A_{l} \\
& =\frac{\beta}{c_{o}{ }^{2}}\left(i \omega_{l}\right)\left[\sum_{k=1}^{m} A_{H_{k}^{l}} A_{k}^{*}\right. \\
& \left.+\sum_{k=1}^{\rho} A_{k} A_{c_{k}^{l}}+\sum_{k=\rho+1}^{m} A_{k} A_{c_{k}^{l}}^{*}\right]
\end{aligned}
$$

In previous research on Cicadas, the researchers only observed the sound waves emitted by Cicadas from an ecological perspective (Debboun \& Strickman, 2013). In addition, the measurement of the frequency of the waves emitted by the cicadas was also observed to find out information on the Cicadas in terms of cicadas behavior (Courtney \& Courtney, 2008). So that no one has tried to physically calculate and directly measure the amount of energy produced by the sound of cicadas. In this study, we try to measure the intensity level generated by Cicadas directly and analyze the amount of energy produced based on the empirical physics formula (Ismail et al., 2016).

\section{METHOD}

In this study, the Intensity Level meter (AMTAST AMF003) was used with time variations (9:00 JST; 13:00 JST; and 15:00 JST). In addition, measurements of variations in air temperature differences (Krisbow Temperature \& Humidity Data Logger) were also carried out, and weather conditions were also considered in data collection using satellite data from Himawari, Japan. Data collection was carried out in the Sanda-Kobe area, Hyogo Prefecture. In this case, there is 1 point with coordinates $34^{\circ} 54^{\prime} 50.3^{\prime \prime} \mathrm{N}$ $135^{\circ} 09^{\prime} 53.8^{\prime \prime} \mathrm{E}$ and time variations at 09:00 am Japan Standard Time (JST), 12:00 pm 
JST, and 3:00 pm JST. The research flow chart can be seen in Figure 2.

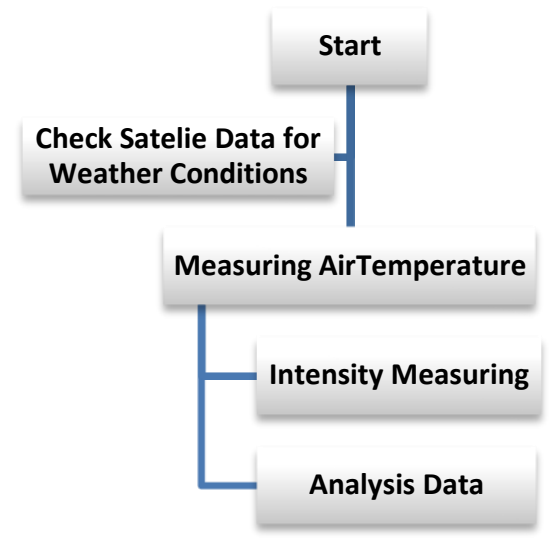

Figure 2. The Research Flow

\section{Specifications of AMTAST AMF003 Sound Intensity Meter:}

$\begin{array}{ll}\text { Measurement Range } & : 30-130 \mathrm{dBA} \\ & 35-130 \mathrm{dBC} \\ \text { Accuracy } & : \pm 1.5 \mathrm{~dB} \\ \text { Digits and Resolution: } & 5 \text { digits and } 0.1 \mathrm{~dB} \\ \text { Frequency response } & : 31.5 \mathrm{~Hz}-8.5 \mathrm{kHz} \\ \text { Measurement Level } & : 30-130 ; 40-90 ; 50- \\ & 100 ; 60-110 ; 80-130 \\ \text { Frequency weighting characteristics: A and C } & : 2 \text { times/second } \\ \text { Sampling time } & : 1 / 2 \text { inch } \\ \text { Microphone / sensor } & : 4 \times 1.5 \mathrm{~V} \text { AA batteries } \\ \text { Power supply } & \text { or } 6 \mathrm{~V} 100 \mathrm{~mA} \text { adapter } \\ \text { Dimensions } & : 256 \times 70 \times 35 \text { mm } \\ \text { Weight } & : 308 \mathrm{~g}\end{array}$

\section{RESULTS AND DISCUSSION \\ Theoretical Analysis}

Waves in their propagation will experience a decrease in intensity (attenuation) due to dispersion and absorption (Hertach et al., 2016). The spread of the wave also causes the intensity to decrease due to the increase in area, which is related to the shape of the wavefront (Sueur \& Sanborn, 2003). However, sound waves produced by crickets are amplified because the waves produced have the same frequency (Sanborn, 2002). It is estimated that in this study, the types of Cicadas insect species have very small variations in one area, especially the location of data collection. One type of Cicadas in the study can be seen in Figure 3.

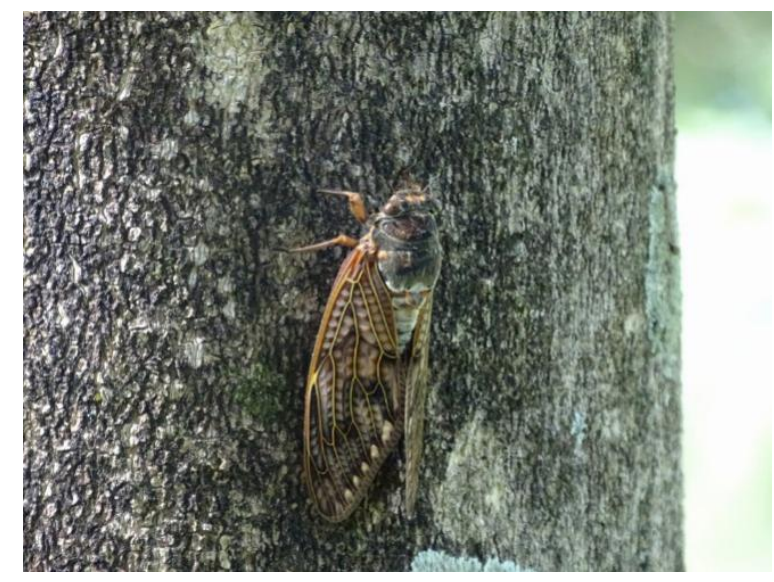

Figure 3. Cicadas at the Location of Sound Wave Data Collection

Generally, in nature, the interaction of sound waves is more than two mutually reinforcing sources. In this case, the researchers estimate only three waves as a test for calculating the energy and phase forms in the graph. In this case, the secondorder nonlinear equation as a unit process will be three-wave interaction. Equations with second-order nonlinear terms can be analyzed by equations (Yang et al., 2014).

$\left\{\begin{array}{l}\frac{d A_{1}}{d x}-i \frac{\omega_{1}}{c} A_{1}+\frac{b \omega_{1}{ }^{2}}{2 \rho_{o} c_{o}{ }^{3}} A_{1}=\frac{\beta}{c_{o}{ }^{2}}\left(i \omega_{1}\right)\left(A_{2}^{*} A_{3}\right) \\ \frac{d A_{2}}{d x}-i \frac{\omega_{2}}{c} A_{2}+\frac{b \omega_{2}{ }^{2}}{2 \rho_{o} c_{o}{ }^{3}} A_{2}=\frac{\beta}{c_{o}{ }^{2}}\left(i \omega_{2}\right)\left(A_{1}^{*} A_{3}\right)(8) \\ \frac{d A_{3}}{d x}-i \frac{\omega_{3}}{c} A_{3}+\frac{b \omega_{3}{ }^{2}}{2 \rho_{o} c_{o}{ }^{3}} A_{3}=\frac{\beta}{c_{o}{ }^{2}}\left(i \omega_{3}\right)\left(A_{1} A_{2}\right)\end{array}\right.$

Where $k_{1}+k_{2}=k_{3}$. In this analysis, the assumption of the difference in sound waves is needed because the distance from the sound source to the receiver (measuring instrument) is different. Even in the measuring instrument, the average value is obtained in 35 seconds. $\omega_{1}$ is a lowfrequency sound wave $(\mathrm{Hz}), \omega_{2}$ is a medium frequency sound wave $(\mathrm{Hz}), \omega_{3}$ is highfrequency sound wave $(\mathrm{Hz})$ so that the analogy in the wave difference can be written as $\omega_{1}<\omega_{2}<\omega_{3}$.

Complex amplitude parsing is required to express acoustic amplitude and frequency 
phase concerning distance (Sanborn, 1997). In this case, the complex amplitude $A_{l}=$ $B_{l} \exp \left(i s_{l}(x)\right)$ and $A_{l}{ }^{*}=B_{l} \exp \left(-i s_{l}(x)\right)$ can be substituted and new equations, namely real and imaginary equations (8). Expression of acoustic amplitude and frequency phase $\omega_{l}$ with the distance can be obtained as follows,

$$
\left\{\begin{array}{l}
\frac{d B_{1}}{d x}+\frac{b \omega_{1}^{2}}{2 \rho_{0} c_{0}^{3}} B_{1}=-\frac{\omega_{1} \beta}{c_{0}^{2}} B_{2} B_{3} \sin \left(s_{3}-s_{2}-s_{1}\right) \\
\frac{d B_{2}}{d x}+\frac{b \omega_{2}^{2}}{2 \rho_{0} c_{0}^{3}} B_{2}=-\frac{\omega_{2} \beta}{c_{0}^{2}} B_{1} B_{3} \sin \left(s_{3}-s_{2}-s_{1}\right) \\
\frac{d B_{3}}{d x}+\frac{b \omega_{3}^{2}}{2 \rho_{0} c_{0}^{3}} B_{3}=-\frac{\omega_{3} \beta}{c_{0}^{2}} B_{1} B_{2} \sin \left(s_{3}-s_{2}-s_{1}\right) \\
\frac{d s_{1}}{d x}-\frac{\omega_{1}}{c_{0}}-\frac{\omega_{1} \beta}{c_{0}^{2}} \frac{B_{2} B_{3}}{B_{1}} \cos \left(s_{3}-s_{2}-s_{1}\right)=0 \\
\frac{d s_{2}}{d x}-\frac{\omega_{2}}{c_{0}}-\frac{\omega_{2} \beta}{c_{0}^{2}} \frac{B_{1} B_{3}}{B_{2}} \cos \left(s_{3}-s_{2}-s_{1}\right)=0 \\
\frac{d s_{3}}{d x}-\frac{\omega_{3}}{c_{0}}-\frac{\omega_{3} \beta}{c_{0}^{2}} \frac{B_{2} B_{3}}{B_{1}} \cos \left(s_{3}-s_{2}-s_{1}\right)=0
\end{array}\right.
$$

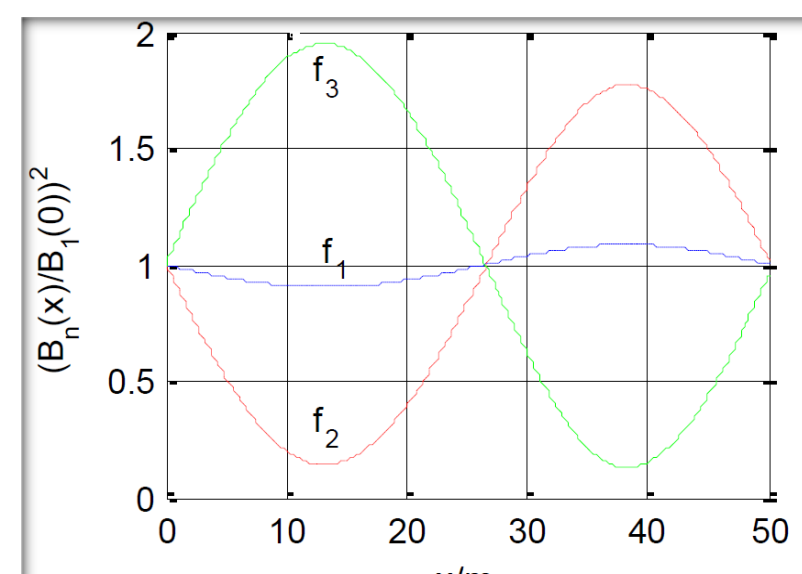

Suppose it is assumed that the parameters of the three waves are $f_{1}=10 \mathrm{kHz}, f_{2}=$ $100 \mathrm{kHz}$, then $f_{3}=f_{1}+f_{2}$. The sound pressure level of the three waves is assumed to be $220 \mathrm{~dB}$, and the initial phase is $s_{1}(x=$ $0)=0, s_{2}(x=0)=\pi / 6, s_{3}(x=0)=$ $\pi / 2$. The results of the derivation of this equation can be expressed in Figure 4.

In this analysis, the assumption of the difference in sound waves is needed because the distance from the sound source to the receiver (measuring instrument) is different (Sanborn et al., 2002). However, in measuring instruments, the average value is obtained in 35 seconds which can be assumed as the real value in the measurement (Stölting et al., 2002)

Figure 4. Energy and Phase Variations of the Interaction Process between Three Waves in the Air

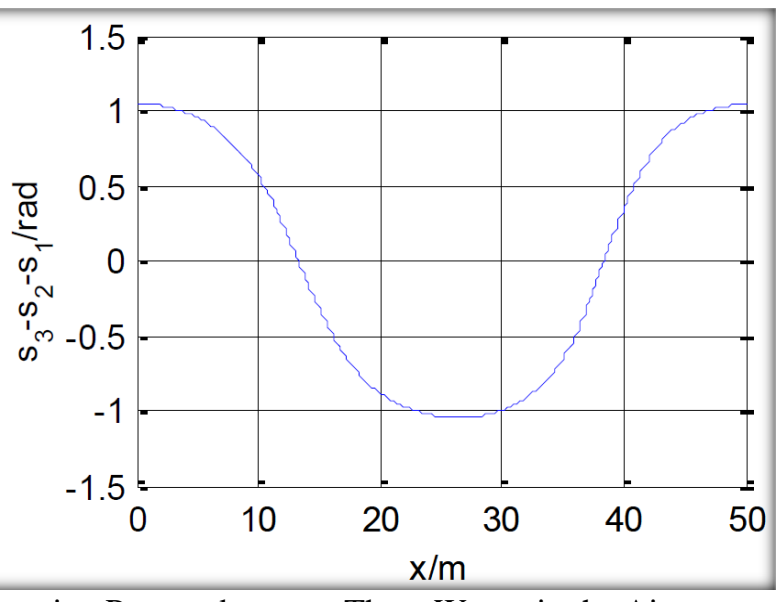

Meteorological Observations Based on the Secondary Data from the Himawari Satellite, Japan

The observations using secondary data from the Himawari satellite, Japan obtained information on the average water vapor flux during the summer from July 15, 2018, to August 15, 2018, in the Japanese region. The central part of the Kansai area, Japan (where includes Hyogo Prefecture, Osaka Prefecture, and Nara Prefecture) experienced the highest flux (Figure 5).
Meanwhile, the results of measurements of total precipitation in the range of July 15 , 2021, to August 15, 2018, have a fairly high rainfall value in the area of the measurement location (Hyogo Prefecture Japan). These results greatly affect the average value of the intensity level in the study area (Figure 6). However, the highest rainfall is found in parts of Shikoku Island and Kii Peninsula, Southwestern Japan. 


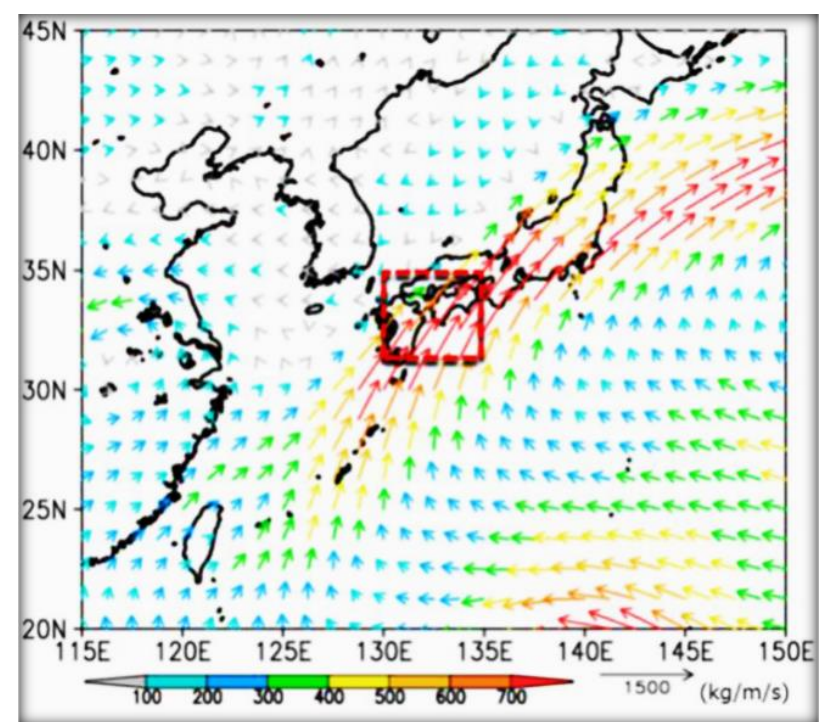

Figure 5. Vertically Integrated Horizontal Water Vapor Flux Averaged from July 15, 2021, to August 15, 2018(Japan Meteorological Agency, 2018).

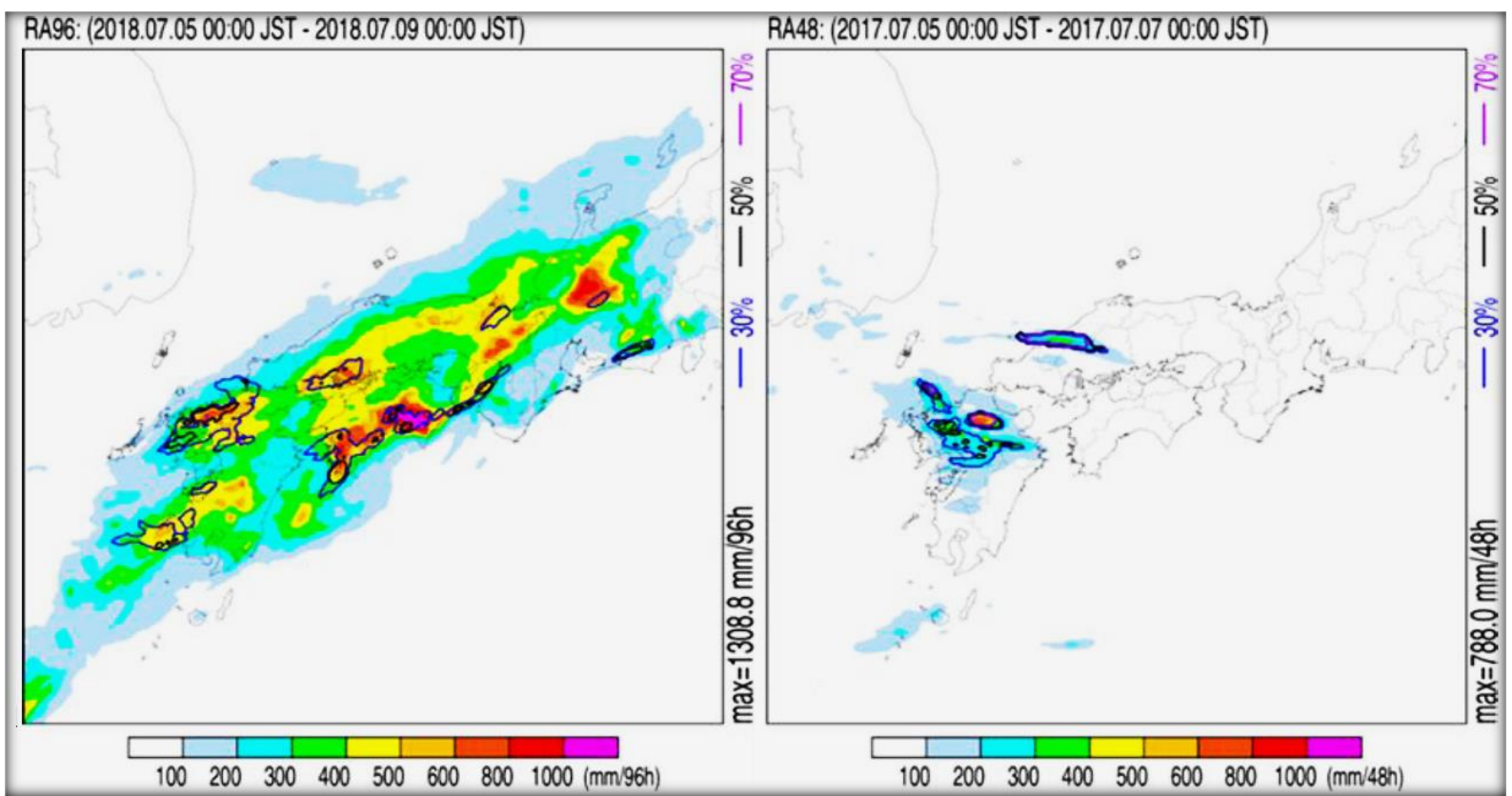

Figure 6. Total Rainfall and Total Ratio in the Rainfall System in the Japanese Region (Japan Meteorological Agency, 2018)

\section{Analysis Results of Average Intensity Level Measurement}

The interpretation of the analysis data can be seen in Figure 7. Overall, the highest intensity level was found at 3:00 pm JST (Figure 7A) with an average temperature of $34.5^{\circ} \mathrm{C}$ and the value of temperature variations ranging from $31^{\circ} \mathrm{C}$ to $38^{\circ} \mathrm{C}$ (Table 1). The value of temperature and intensity level is very consistent and has a positive correlation. On the other hand, based on the interpretation of Figures 7B, 7C, and7D, the trend at 3:00 pm JST decreased concerning day change. Meanwhile, at 09:00 am JST and 12:00 pm JST, it did not show a decrease concerning changes in days (a total of 31 days)

These results show that the change of day factor can affect the intensity level of sound waves. This result has a positive correlation with the observed water vapor flux value. In the central region of Japan (Kansai), the 
months of July-August are the highest intensity level values produced from cicadas. This value depends on the size of the sun and the flux of water vapor (Heath, 1987). Although the intensity of rainfall affects the decrease in the intensity level of cicadas sound waves, the low level of rainfall can affect that July-August is the most optimal intensity level value.

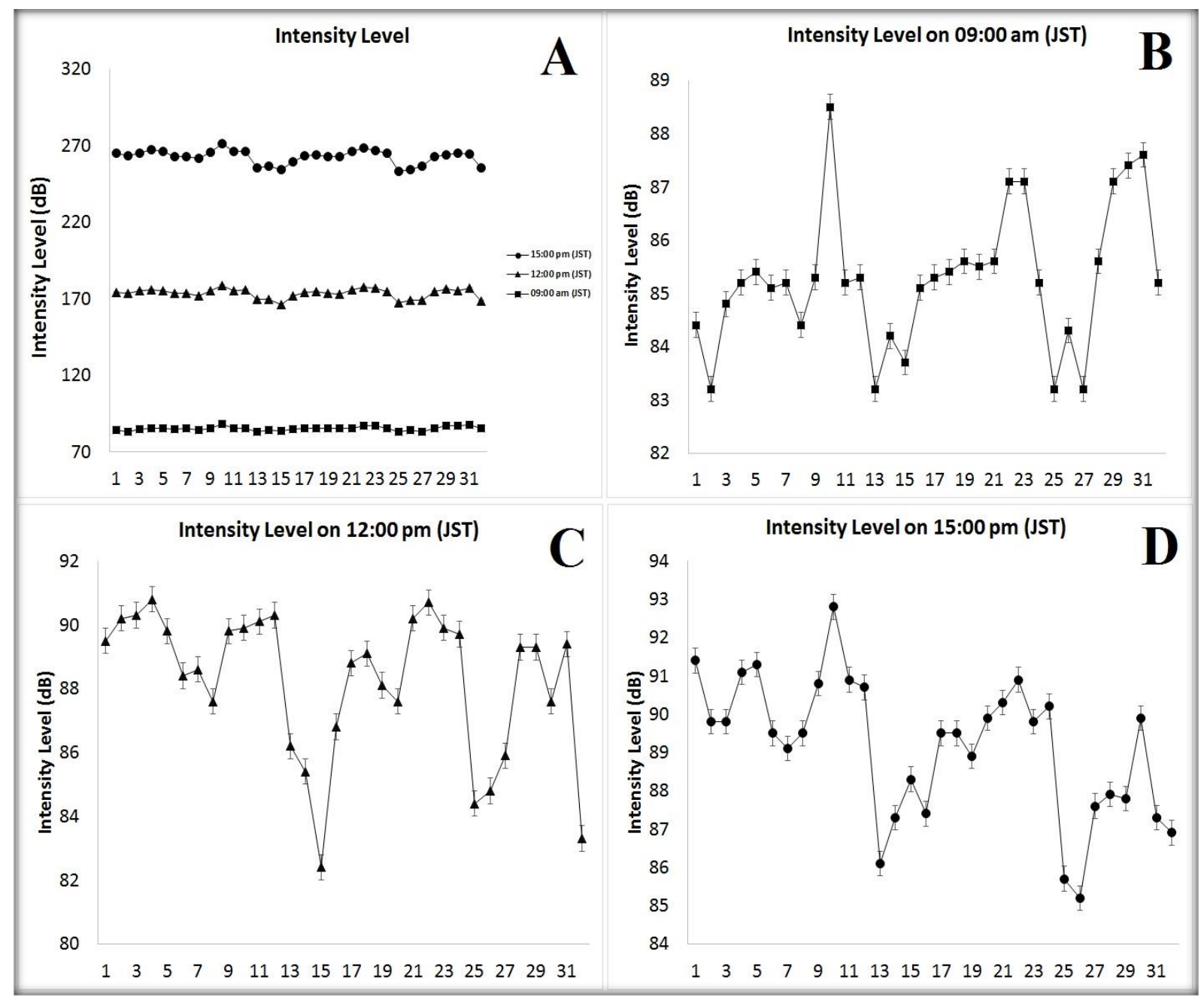

Figure 7. The Results of the Interpretation of the Overall Intensity Level and Based on the Difference of Three Times

Based on the interpretation of the acoustic (sound) Intensity and Power values, it can be seen (Figure 8A) that at 09:00 am JST, it has a lower value than 12:00 pm JST and 3:00 pm JST. However, the value at 09:00 am JST has a variation that tends to be stable compared to others. On the other hand, although the difference in intensity value variations between 12:00 pm JST and 3:00 pm JST is not too far (Figure 8B), the variation in acoustic power values tends to be larger. This explains that slightly different intensity levels can affect large changes in acoustic power or the sound produced (Khalil \& Santos, 2014). 


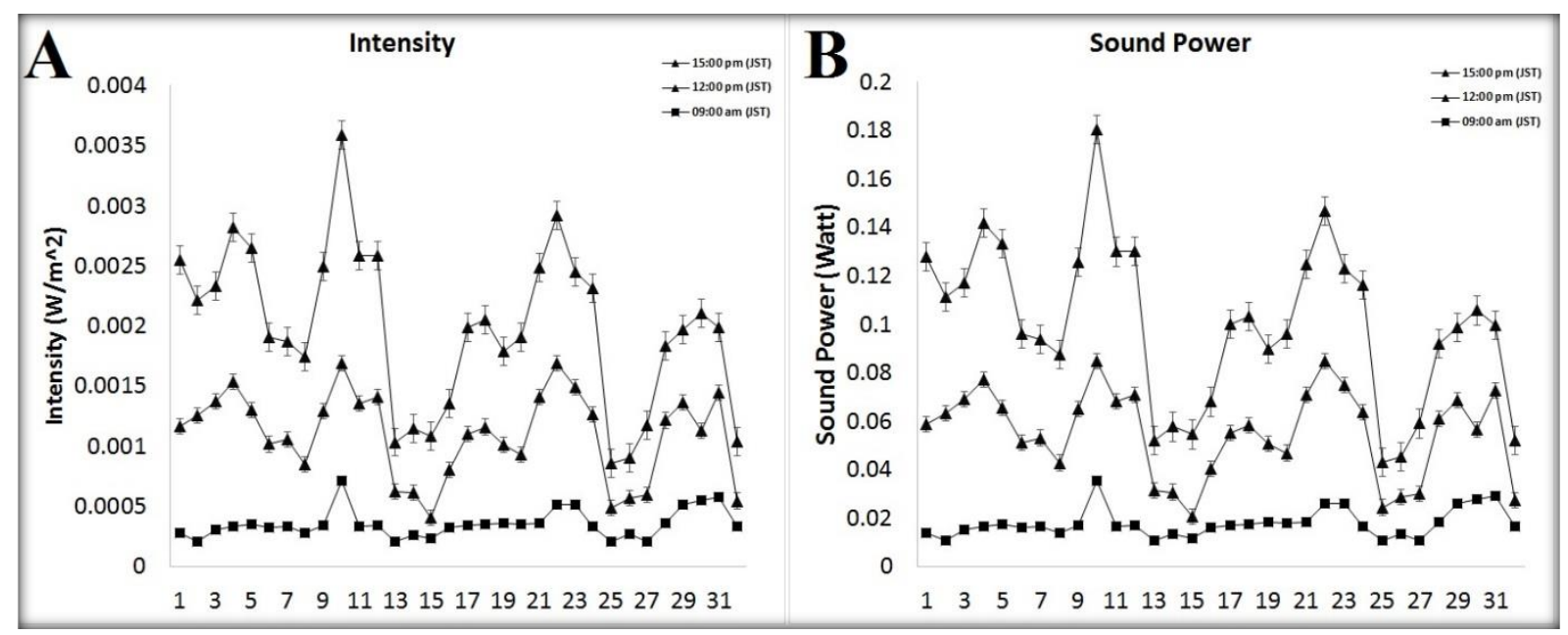

Figure 8. Interpretation Results of the Average Intensity and Acoustic Power for 31 days (July 15 - August 15, 2018)

The amount of energy obtained from the sound of Cicadas can be measured using the Intensity Meter Level (Anshar et al., 2016).The energy value obtained from the sound of Cicadas in the summer in the subtropical region, especially the Sanda, Hyogo, Japan area, gets a fairly high value (Figure 9). Generally, variations in energy of 4-6 Joules can be used as lighting using LEDs.

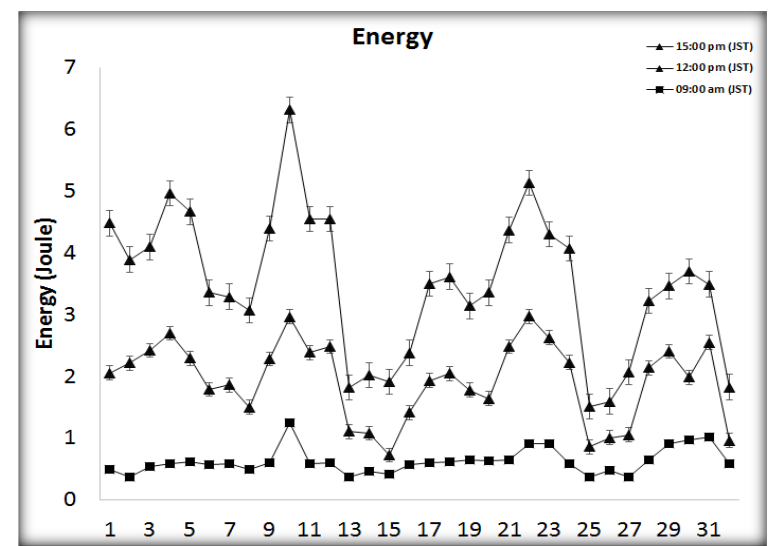

Figure 9. Calculation of the Average Value of Energy Obtained from Cicadas Sound Waves with Three-Time Differences for 31 Days

On the other hand, the use of parabolic as a focus in measuring sound waves may increase the level of intensity obtained. In previous studies, the use of parabolic in capturing cellphone signals has been proven to increase cellphone signals because parabolic has a concept like a concave mirror that focuses all the waves obtained at a single point (focal point) (Varga \& Török, 2000). Then at that point, a receiver is installed as a signal or wave catcher.

\section{CONCLUSION AND SUGGESTION}

Based on the measurement results in Table 1, the average value of the intensity level in 1 measurement is obtained with a minimum value variation of $82.4 \mathrm{~dB}$ and a maximum of $92.8 \mathrm{~dB}$. These results affect the intensity value with a minimum value variation of $0.00017 \mathrm{~W} / \mathrm{m}^{2}$ and a maximum of $0.0019 \mathrm{~W} / \mathrm{m}^{2}$. While the results of the analysis of the calculation of sound power have a value variation from 0.0087 to 0.0957 watts with an energy value of 0.305 to 3.305 J. Based on interpretation results of intensity level trend by change of day, at 3:00 pm JST it decreased with the change of day. Meanwhile, at 09:00 am JST and 12:00 pm JST, it did not show a decrease concerning changes in days (a total of 31 days). These results show that temperature changes (towards autumn) can affect the intensity level of sound waves. In addition, slightly different intensity levels can affect large changes in acoustic power or the sound produced.

In researching the sound waves produced by cicadas, it is hoped that they can be measured after using parabolic as a sound wave catcher in the future. The measurement of the intensity level can produce a greater 
value. In addition, the use of a prototype sound wave to energy converter is expected to prove that the sound waves produced are capable of producing electrical energy.

\section{ACKNOWLEDGMENT}

The researchers thank Nishimura Foundation Scholarship Japan for supporting research in Sanda, Hyogo Prefecture, Japan.

\section{RESEARCHERS' NOTE}

The researchers declare that there is no conflict of interest regarding the publication of this article. The researchers confirm that the data and the paper are free of plagiarism.

\section{AUTHOR CONTRIBUTIONS}

EK presents the initial idea. KY and MI determine the research method used. RN analyzes theory. RU presents figures. I make research results and conclusions.

\section{REFERENCES}

Anshar, M., Ani, F. N., \& Kader, A. S. (2016). Electrical energy potential of rice husk as fuel for power generation in Indonesia. ARPN Journal of Engineering and Applied Sciences, 11(6), 3616-3624.

Courtney, M., \& Courtney, A. (2008). The ballistic pressure wave theory of handgun bullet incapacitation. ArXiv Preprint ArXiv, 1-8. https://arxiv.org/ftp/arxiv/papers/0803/ 0803.3053.pdf

Debboun, M., \& Strickman, D. (2013). Insect repellents and associated personal protection for a reduction in human disease. Medical and Veterinary Entomology, 27(1), 1-9. https://doi.org/10.1111/j.13652915.2012.01020.x

Fonseca, P. J., \& Correia, T. (2007). Effects of temperature on tuning of the auditory pathway in the cicada Tettigetta josei (Hemiptera, Tibicinidae). Journal of Experimental Biology, 210(10), 18341845.

https://doi.org/10.1242/jeb.001495
Gheibi, A., \& Hedayat, A. (2020). Ultrasonic imaging of microscale processes in quartz gouge during compression and shearing. Journal of Rock Mechanics and Geotechnical Engineering, 12(6), 1137-1151. https://doi.org/10.1016/j.jrmge.2020.03 .011

Heath, B. R. C. (1987). Basic Ground-Water Hydrology (Fourth Edi). USGS.

Hertach, T., Puissant, S., Gogala, M., Trilar, T., Hagmann, R., Baur, H., Kunz, G., Wade, E. J., Loader, S. P., Simon, C., \& Nagel, P. (2016). Complex within a complex: Integrative taxonomy reveals hidden diversity in Cicadetta brevipennis (Hemiptera: Cicadidae) and unexpected relationships with a song divergent relative. PLOS ONE, 11(11), $1-41$.

https://doi.org/10.1371/journal.pone.01 65562

Huis, A. V., Itterbeeck, J, V., Klunder, H., Mertents, E., Halloran, A., Muir, G., \& Vantomme, P. (2013). Edible insects: Future prospects for food and feed security. WageningenUR.

Ismail, O., Urbanus, M., Murage, H., \& Francis, O. (2016). Conversion of rice husks into an energy source through gasification technology. International Journal of Science and Research (IJSR), 5(9),

1264-1268. https://doi.org/10.21275/ART20161814

Japan Meteorological Agency. (2018). Primary factors behind the heavy rain event of july 2018 and the subsequent heatwave in Japan from mid-july| World Meteorological Organization. July, 124.

Josephson, R. K., \& Young, D. (1979). Body temperature and singing in the bladder cicada, cystosoma saundersii. Journal of Experimental Biology, 80(1), 69-81. https://doi.org/10.1242/jeb.80.1.69

Khalil, M. A., \& Santos, F. M. (2014). On the depth to anomaly estimation using Karous and Hjelt filter in VLF-EM data. Arabian Journal of Geosciences, 7(10), 
4355-4359.

https://doi.org/10.1007/s12517-0131110-3

Mashhadi, S. K. M, Yadollahi, H., \& Mashhad, A. M. (2016). Design and manufacture of TDS measurement and control system for water purification in reverse osmosis by PID fuzzy logic controller with the ability to compensate effects of temperature on measurement. Turkish Journal of Electrical Engineering and Computer Sciences, 24(4), 2589-2608. https://doi.org/10.3906/elk-1402-65

Sanborn, A F. (2002). Cicada thermoregulation (Hemiptera, Cicadoidea). Denisia, 4(176), 455-470.

Sanborn, A. F. (1997). Body temperature and the acoustic behavior of the cicada Tibicen winnemanna (Homoptera: Cicadidae). Journal of Insect Behavior, 10(2), 257-264. https://doi.org/10.1007/BF02765558

Sanborn, A. F., Noriega, F. G., \& Phillips, P. K. (2002). Thermoregulation in the cicada Platypedia putnami variety lutea (Homoptera: Tibicinidae) with a test of a crepitation hypothesis. Journal of Thermal Biology, 27(5), 365-369. https://doi.org/10.1016/S03064565(02)00004-9

Shi, Y., \& Liu, X. (2019). Research on the literature of green building based on the web of science: A scientometric analysis in citespace (2002-2018). Sustainability (Switzerland), 11(13), 122. https://doi.org/10.3390/su11133716 Stölting, H., Moore, T. E., \& Lakes-Harlan, R. (2002). Substrate vibrations during acoustic signalling in the cicada Okanagana rimosa. Journal of Insect Science, 2(2), 1-22. https://doi.org/10.1093/jis/2.1.2

Sueur, J., \& Sanborn, A. F. (2003). Ambient temperature and sound power of cicada calling songs (Hemiptera: Cicadidae: Tibicina). Physiological Entomology, 28(4), 340-343. https://doi.org/10.1111/j.13653032.2003.00345.x

Varga, P., \& Török, P. (2000). Focusing of electromagnetic waves by paraboloid mirrors. I. Theory. J. Opt. Soc. Am, 17(1), 2081-2089.

WHO. (2003). Hazard Characterisation for Pathogens in Food and Water. In Microbiological Risk Assessment Series (Issue 3, 1-61). WHO Library Cataloguing.

Yang, D., Jiang, W., Shi, S., Zhang, H., \& Jin, S. (2014). Theory and experiment of the resonance sound wave interactions in water. Proceedings of Meetings on Acoustics, 21(1), 1-11. https://doi.org/10.1121/1.4882077. 